\title{
HORIZONTES DE DIÁLOGO EM EDUCAÇÃO AMBIENTAL: CONTRIBUIC̣̃̃ES DE MILTON SANTOS, JEAN-JACQUES ROUSSEAU E PAULO FREIRE
}

\author{
Sandro de Castro Pitano* \\ Rosa Elena Noal**
}

RESUMO: Dialogando interdisciplinarmente com referenciais teóricos da Geografia, da Educação e da Filosofia, buscamos contribuir com os debates em torno da "Educação Ambiental", propondo novas perspectivas de análise ancoradas no pensamento político e pedagógico de Milton Santos, Jean-Jacques Rousseau e Paulo Freire. Entendemos que, se o fator determinante para o esgotamento dos elementos vitais do meio geográfico e das condições de sustentabilidade da vida na terra é o resultado das relações estabelecidas entre os homens, em sistemas sociais culturalmente heterogêneos, precisamos modificar nossa perspectiva de análise diante dos problemas ambientais na educação. O foco passa a ser não mais a dinâmica ser humano x natureza ou, ainda, sociedade x natureza, e sim sociedade x meio geográfico, o que sugere uma educação "socioambiental".

Palavras-chave: Milton Santos; Freire; Rousseau; Educação Ambiental.

\section{DIALOGUE PERSPECTIVES IN ENVIRONMENTAL EDUCATION: CONTRIBUTIONS OF MILTON SANTOS, JEAN-JACQUES ROUSSEAU AND PAULO FREIRE}

ABSTRACT: Through interdisciplinary dialogue with theoretical references of Geography, Education and Philosophy, we aim at contributing to debates about "environmental education", proposing new perspectives of analysis supported by the political thoughts and teachings of Milton Santos, Jean-Jacques Rousseau and Paulo Freire. We believe that, if the determinant factor for the extinction of the vital elements of the geographic means and the sustainable conditions of life on planet Earth is the result of relations established between human beings, in culturally heterogeneous social systems, a change of point of view is necessary in the face of environmental problems in the field of education. This way, the focus goes from the dynamic of human being $\mathrm{x}$ nature, or, still, society $\mathrm{x}$ nature, to society x geographic means, what suggests a "socioenvironmental" education.

Keywords: Milton Santos; Freire; Rousseau; Environmental Education.

* Doutor em Filosofia da Educação pela Universidade Federal do Rio Grande do Sul (UFRGS); Professor Adjunto do Instituto de Ciências Humanas (ICH) da Universidade Federal de Pelotas (UFPel) e do Programa de Pós-Graduação em Geografia - Mestrado (FURG/UFPel).E-mail: spitano.unipampa@ufpel.tche.br

* * Doutora em Geografia pela Universidade de São Paulo (USP); Professora Adjunta do Instituto de Ciências Humanas (ICH) da Universidade Federal de Pelotas (UFPel) e do Programa de Pós-Graduação em Geografia - Mestrado (FURG/UFPel). 


\section{Introdução}

O diálogo interdisciplinar com referenciais teóricos da Geografia $^{1}$, da Educação e da Filosofia permeia este ensaio, através do qual buscamos sistematizar e propor novas perspectivas de análise para a "Educação Ambiental", ancoradas no pensamento político e pedagógico de Milton Santos, Jean-Jacques Rousseau e Paulo Freire. A abordagem é interdisciplinar no sentido de propor a complementação entre áreas do conhecimento reconhecidamente dialógicas e justifica-se pela afinidade que os aspectos epistemológicos e metodológicos, tipificantes de cada uma das ciências arroladas, revelam diante do objeto de estudo, enriquecendo sua análise. A Geografia se destaca porque, tendo como preocupação central as relações entre os seres humanos e o seu meio, não apenas oportuniza o surgimento de novos modos de enfrentamento das questões ambientais no campo educacional, como por essência o exige. Além disso, como disciplina obrigatória nos ensinos fundamental e médio, representa uma possibilidade constante de diálogo junto às novas gerações acerca dos problemas socioambientais, quiçá sob um enfoque crítico e problematizador, considerando a educação escolar tal como está sendo. Perspectiva crítica que se robustece pelo vigor da análise filosófica, amalgamando as contribuições de cada ciência, superando particularismos e evitando estatuir quaisquer traços hierárquicos nas reflexões que logramos desenvolver.

Com relação aos autores, acredita-se que Rousseau, Santos e Freire oferecem subsídios capazes de elevar o debate educacional, no que diz respeito às questões ambientais. Diante da imperiosa necessidade de avançarmos nesse terreno, adentramos primeiro no pensamento rousseauniano, dedicando especial ênfase à sua concepção de homem, natureza e sociedade. Tudo isso sem minimizar a contundente crítica que desenvolve acerca da educação escolar que lhe foi contemporânea (cujos resquícios talvez ainda se façam presentes). A seguir, Milton Santos embasa as reflexões sobre a ocupação e a transformação do espaço, em uma abordagem geográfica radicalmente crítica e comprometida com as problemáticas sociais do tempo presente. E Freire, finalmente, não apenas por ter demonstrado uma intensa e vigorosa atitude combativa aos problemas resultantes da ação desumana sobre o meio em seus últimos escritos (À sombra desta mangueira, Pedagogia da autonomia e Pedagogia da indig- 
nação), cuja apreensão histórica da existência jamais dissocia a libertação humana da busca por um planeta sustentável. Sua análise mantém em relevo a ideia de que os problemas ambientais, na sua maioria, não são mero resultado de fenômenos naturais ou de forças divinas, mas, sim, de intervenção humana, cujas intencionalidades respondem a um modelo de vida predatório, produzido ao longo dos tempos. Tampouco somente pela sua rigorosa concepção de natureza humana, em processo de vir-a-ser no mundo e com o mundo, fazendo-se pela educação que, respeitosa dessa natureza, é problematizadora em sua radicalidade. Mas é, sobretudo, pelo profundo respeito que nutre pela vida em todas as suas formas que constitui uma referência indispensável para este estudo.

\section{Rousseau e as relações entre homem, sociedade e natureza}

O desenvolvimento (histórico) da humanidade possui como característica constante a apropriação e a transformação do espaço (com exceção dos contextos habitados pelos povos indígenas, cujo modo de vida em linhas gerais se baseava na harmonia de aprender, fazer e usufruir, ligados de forma respeitosa à Terra). O processo acelerado de industrialização, que lança raízes desde os séculos XVII e XVIII, teve como marca trágica o desrespeito aos fenômenos e aos elementos naturais. Possuindo uma dinâmica extensiva e intensiva, por ampliar concomitantemente a expansão territorial e as condições tecnológicas para a sua exploração, esse processo jamais teria feições equânimes no que diz respeito aos diferentes grupos espalhados pela superfície terrestre. Tornou-se cada vez mais desigual diante do distinto ritmo de seus desenvolvimentos. Como resultado, avançamos da apropriação e da exploração do espaço para uma ação paralela de exploração dos outros seres humanos, como destaca Rousseau (1999a, p. 213):

Mas, a partir do instante em que um homem necessitou do auxílio do outro, desde que percebeu que era útil a um só ter provisões para dois, desapareceu a igualdade, introduziu-se a propriedade, o trabalho tornou-se necessário e as vastas florestas se transformaram em campos risonhos que cumpria regar com o suor dos homens e nos quais logo se viu a escravidão e a miséria germinarem e medrarem com as searas. (ROUSSEAU, 1999a, p. 213) 
Conforme o autor, em sua fase primitiva, o ser humano teria vivido em um estágio pré-social - o estado de natureza -, em que homem e ambiente mantinham uma relação de plena harmonia ${ }^{2}$. Nessa época, o homem vivia em paz consigo mesmo, solitário, tranquilo e ocioso, guiado por instintos e preocupado somente com a própria conservação. As transformações na paisagem eram insignificantes, pois a interferência da ação humana no espaço correspondia ao instintivo e reduzido grupo de necessidades básicas a serem supridas. Entretanto, a ocorrência de significativos fenômenos de ordem climática sobre o ambiente teria provocado uma ruptura, seguida de transformações radicais no modo de vida da humanidade, que culminaram com o início da convivência coletiva. As alterações causadas pelos fenômenos climáticos sobre o habitat dos homens impuseram-lhes novas necessidades vitais, obrigando-os a desenvolver condições cada vez mais artificiais para tornar possível a subsistência e a consequente continuidade da espécie, as quais seriam possíveis somente através da vida coletiva - a associação. O que o autor do Contrato Social chama de "bondade natural" corresponde ao sentido de conservação da espécie, voltado tanto para o indivíduo (autoconservação) quanto para os demais seres humanos, manifestado pela "repugnância natural a ver perecer ou sofrer qualquer ser sensível, principalmente os nossos semelhantes" (ROUSSEAU, 1999a, p. 154), ao que denominou piedade. Ambos os sentimentos são inerentes ao homem e sempre estiveram nele presentes por natureza, antecedendo a razão e, consequentemente, a sociabilidade. Constatando os princípios sensíveis da espécie em estado natural, ele ainda agrega um terceiro, não menos relevante para a conservação humana face às dificuldades físico-espaciais enfrentadas, a perfectibilidade, faculdade inata de poder aperfeiçoar-se.

Hipoteticamente salientadas pelo autor, tais dificuldades teriam surgido no decorrer da história evolutiva, agregando coerência ao seu pensamento acerca das transformações que provocaram a saída do homem do estado de natureza para o de sociedade. Embora soe contraditório, Rousseau entende que mesmo em sociedade os homens mantêm tais sentimentos, aos quais se somaram a sociabilidade e a razão, donde emanaram tantos outros. E a inexplicável e imprevisível interação de todos caracteriza e diferencia de forma incisiva o homem social do homem natural. É importante salientar que, dos três princípios originais (bondade natural, piedade e perfectibilidade), uns acabam minimizados, 
ao passo que outros ganham vulto maior e determinam, por isso, uma diversidade tão ampla entre os dois estágios da história humana, bem como entre os homens já em sociedade. É bem provável que os sentidos de conservação da espécie corporificados pela preferência de si mesmo, tenham se sobreposto à piedade, ocorrendo o mesmo com a perfectibilidade.

Portanto, frente ao espaço vital que antecede sua capacidade reflexiva e impulsionado por necessidades inesperadas, o homem se associa, produzindo meios técnicos para, de forma mais efetiva, intervir nesse espaço e imprimir-lhe uma paisagem humanizada. A multiplicação das necessidades artificiais desenvolveu no ser humano o gosto pelo supérfluo, representado pelo luxo, que provocou desde então uma competição desigual pela sua obtenção, ou seja, os conflitos sociais. E assim como os territórios e os recursos neles contidos são vistos como "espaço a se ganhar" (MORAES, 1994, p. 37), as pessoas também passam a ser consideradas instrumentos dessa conquista. Em consequência, para resolver os constantes conflitos entre os indivíduos, foi preciso instituir um sistema de normas regulamentadoras para as associações iniciantes. Para Rousseau, esse procedimento teria partido dos poderosos com o fito de garantir e ampliar, se possível, suas posses. Os homens, em sua maioria, foram iludidos para que assinassem um pacto de direitos amplamente seletivos e desfavoráveis aos fracos. Porém, não se deve concluir, apressadamente, que a sociedade seja considerada má por essência, já que ela é um ente necessário face ao progresso do gênero humano. O que ela precisa é ser bem-formada, considerando como um dos seus pilares básicos a liberdade, fruto da justa igualdade entre as pessoas. E a formação de uma sociedade igualitária, logo, mais justa, estaria vinculada à formação moral dos seus membros, tarefa que compete, indiscutivelmente, à educação.

Ao produzir o Emílio ${ }^{3}$, Rousseau estabelece as bases de uma educação capaz de formar o verdadeiro homem, pois "apesar de tantos escritos", lembra ele, "a primeira de todas as utilidades, que é a de formar os homens, ainda está esquecida" (1999b, p. 4). Assim, formar o homem é a primeira tarefa, a segunda é formar o cidadão, "pois não se pode fazer os dois ao mesmo tempo". Refutando a educação praticada na sua época, que "só serve para criar homens de duas faces" (1999b, p. 13), o autor expõe aquilo que é, para ele, a maneira ideal de educar o ser humano, de formá-lo. Com efeito, descreve no Emílio a evolução de um aluno desde 
a infância até a vida adulta, sempre baseado na natureza como metodologia de ensino. Sua obra pedagógica é composta por um conjunto de métodos, princípios educativos que objetivam garantir ao educando uma formação individual solidamente virtuosa, para que ele pudesse enfrentar a sociedade tal como ela é. É por isso que Rousseau propõe educar o indivíduo de acordo com a natureza, para atingir posteriormente o social. Educando o homem (Emílio), a sociedade dificilmente seria capaz de corrompê-lo. Emílio seria, assim, um selvagem para viver nas cidades. Entretanto, seguindo a linha pedagógica proposta, Rousseau o deixaria enfrentar a vida social somente quando tivesse consciência suficiente para julgar as relações temerárias que se estabelecem não só entre seus semelhantes, mas também destes em relação ao próprio espaço vital. Percebese que a perspectiva antropológica rousseauniana contempla uma nova ruptura ontológica no ser humano, alterando sua natureza de forma dialética, segundo a qual os sentimentos naturais fossem conservados e transformassem sua concepção de todo, anteriormente existente enquanto existência individual, em uma ideia de parte indivisível de um todo maior, que é a existência social4. Esse é o papel que cabe à educação no pensamento rousseauniano: formar o homem de acordo com sua nova condição, permitindo-lhe harmonizar-se com os semelhantes, respeitandoos, ao mesmo tempo em que a consciência de uma evolução tecnológica se torna item elementar na formação moral, no intuito de, novamente, garantir a continuidade da espécie. Parece que Rousseau antevia a possibilidade da ocorrência de novos cataclismos provocados pelo próprio agir humano sobre o seu meio vital. As condições contemporâneas de vida em sociedade assim o revelam, como expressa Mendonça (1994):

Ao lado do crescente contingente populacional, o desenvolvimento da ideologia do consumismo pós anos 50 tem exacerbado as diferenças entre condições de vida, o que tem gerado extremos na qualidade da miséria humana e ao mesmo tempo a concentração de riquezas, ilustrada pelo aparecimento de verdadeiros magnatas. (MENDONÇA, 1994, p. 12)

As sociedades cujo modo de vida se enquadra na perspectiva "ocidental" tendem a considerar o "natural" como inferior diante do cultural, o que demonstra uma posição de radical estranhamento entre os seres humanos e a natureza. Rousseau se coloca na contramão dessa corrente, afirmando que tanto a ciência quanto as artes são maléficas diante 
da natureza humana originária. O curioso é que, embora emergindo no auge da Revolução Industrial (séc. XVIII), esse posicionamento vai de encontro à tese que sustentaria desde então todo o desenvolvimento do sistema capitalista: a dominação da "natureza" como meio de garantir o progresso da humanidade. Talvez o filósofo genebrino antevisse que, sendo o homem também natureza, dominá-la acarretaria (e justificaria) a dominação recíproca do ser humano pelos próprios semelhantes. Seu posicionamento apologético do convívio harmônico entre as espécies, ainda no final da vida, reflete a identificação profunda com a natureza:

As árvores, os arbustos, as plantas são o enfeite e a vestimenta da terra. Nada é tão triste como o aspecto de um campo nu e sem vegetação, que somente expõe diante dos olhos pedras, limo e areias. Mas, vivificada pela natureza e revestida com seu vestido de núpcias no meio do curso das águas e do canto dos pássaros, a terra oferece ao homem, na harmonia dos três reinos, um espetáculo cheio de vida, de interesse e de encanto, único espetáculo do mundo de que seus olhos e seu coração não se cansam nunca. (ROUSSEAU, 1995, p. 93)

Ao não considerar o homem social por origem, mas que acaba se tornando, artificialmente, durante o processo histórico, Rousseau contraria a concepção corrente, tão cara ao pensamento ocidental desde Aristóteles, que compreende o humano como um ser originalmente social. O ponto de vista rousseauniano também é compactuado por Freire (2000a, p. 28) quando este, discordando (em parte) de Aristóteles, afirma que "continuamos a ser, sim, aquilo em que nos tornamos: animais políticos”.

\section{Avanço tecnológico, desigualdade e meio}

Baseado no até então exposto, cremos ter evidenciado que o fator determinante para o esgotamento dos elementos vitais da natureza e das condições de sustentabilidade da vida na terra é resultado das relações estabelecidas entre os homens, em sistemas sociais culturalmente heterogêneos. Por esse prisma há um deslocamento do foco, que passa a ser não mais a dinâmica ser humano $\mathrm{x}$ natureza $\mathrm{e}$, sim, sociedade $\mathrm{x}$ natureza. Não esqueçamos de que o ser humano é e sempre será parte da "natureza", considerando-a como fonte, existência primeira de tudo o que 
há no mundo. O que ocorre é um gradativo afastamento entre os modos de vida natural e social, principalmente no que se refere às necessidades atuais e aquelas originárias da espécie. As necessidades foram sendo multiplicadas artificialmente sem que fossem avaliadas as possibilidades que o meio teria para provê-las. Ao colocar a questão ambiental nos termos de sociedade e não mais de homem, problematiza-se não apenas o viés tecnicista, mas também o aspecto político, o que salienta, de imediato, a responsabilidade do modo de produção capitalista e o seu objetivo maior - o lucro, elemento determinante na exploração do espaço em sua totalidade, incluindo homens e mulheres. Como afirma Casseti (1991):

À medida que a propriedade privada é desenvolvida (apropriação privada da natureza), o acúmulo de capital se torna conseqüência, o que além de responder pelo processo de degradação ambiental, responde pelo antagonismo de classe. (CASSETI, 1991, p. 25)

Com o advento e o aprimoramento das técnicas, cujo processo em si não pode ser responsabilizado pelo nosso modo de vida exploratório e poluidor, a humanidade foi gradativamente transformando o espaço vivido. Primeiro, como vimos, de forma lenta e sutil, imprimindo maior velocidade e profundidade à medida que as técnicas, entendidas como o "conjunto de meios instrumentais e sociais, com os quais o homem realiza sua vida, produz e, ao mesmo tempo, cria espaço" (SANTOS, 2002, p. 29), foram sendo aprimoradas. Os objetos contidos em nosso meio não mais se determinam por si mesmos, sendo valorados e organizados segundo a lógica da ação humana para o seu uso. E o meio (antes "natureza") acaba se constituindo num sistema de objetos em que tudo possui intencionalidade e valor.

Em síntese, no meio natural as relações humanas com a natureza eram pautadas pela "harmonia socioespacial (...) respeitosa da natureza herdada, no processo de criação de uma nova natureza" (SANTOS, 2002, p. 236). Com o advento da mecanização, a ação antrópica sobre o espaço (e não mais sobre a natureza em seu sentido original) tornou-se cada vez mais poderosa. Essa artificialização do modo de interferir no espaço, transformando-o, funda o que o geógrafo brasileiro denomina de meio técnico, que, por sua vez, inaugura o desequilíbrio ambiental: 
Os objetos técnicos e o espaço maquinizado são locus de ações "superiores", graças a sua superposição triunfante às forças naturais. Tais ações são, também, consideradas superiores pela crença de que ao homem atribuem novos poderes - o maior dos quais é a prerrogativa de enfrentar a Natureza, natural ou já socializada, vinda do período anterior, com instrumentos que já não são prolongamento do seu corpo, mas que representam prolongamentos do território, verdadeiras próteses. Utilizando novos materiais e transgredindo a distância, o homem começa a fabricar um tempo novo, no trabalho, no intercâmbio, no lar. Os tempos sociais tendem a se superpor e contrapor aos tempos naturais. (SANTOS, 2002, p. 236)

Desde o vertiginoso desenvolvimento científico percebido após a Segunda Guerra Mundial, as técnicas vêm se tornando cada vez mais eficientes em relação à intencionalidade do mercado, seu gestor principal. Aliadas à capacidade informacional que multiplica e aprofunda a ação transformadora do espaço, globalizando as relações de produção e consumo, as técnicas transformam-se "no meio de existência de grande parte da humanidade" (SANTOS, 2002, p. 239). O local, subordinado ao global, passa a ser explorado economicamente por atores externos, justificando por que, não raro, o desequilíbrio socioambiental pode aumentar em paralelo ao crescimento econômico de um lugar. Ao mesmo tempo em que o capital globalizado se torna extraterritorial, os problemas ambientais gerados localmente respondem a intencionalidades distantes, o que Santos (SANTOS, 2002, p. 254) denomina a "desterritorialização do desastre ecológico". Toda essa dinâmica desnuda o problema socioambiental em sua radicalidade: a ideologia dominante propagando, contraditoriamente, o desenvolvimento ilimitado e o comportamento consumista, mesmo diante de uma base finita de recursos.

Diante do exposto, pode-se afirmar que atualmente não existe mais um espaço natural; mesmo as regiões mais remotas da terra, cujas condições de vida se mostram extremamente adversas, impedindo a habitação humana, são delimitadas territorialmente, mapeadas. Tal constatação sugere que o termo "natureza" seja ressignificado, pois vivemos num espaço repleto de objetos técnicos, o meio geográfico. Se mesmo elementos considerados "naturais", como um rio ou mesmo o ar, foram apropriados e revestidos de intencionalidade pela ação humana, acaba sendo incoerente continuarmos insistindo em duas abordagens usuais no momento: a primeira, que trata as agressões causadas pela sociedade em seu meio como "problema ambiental", e a segunda, complementar, que 
afirma ser preciso repensar e reordenar a ação do homem (sociedade) sobre a natureza. Ora, o termo "ambiental" escamoteia o aspecto social, que inclui, obrigatoriamente, as relações predatórias mantidas entre os próprios homens. Ao centralizar a análise dos objetos "naturais", esse discurso "nada ingênuo" promove um reducionismo na capacidade crítica daqueles que com tais problemas se revoltam após compreendê-los mais radicalmente. Por fim, despolitizado, provoca mais um "encurtamento" temporal, como se os problemas não fossem, assim como os homens, históricos. Como a realização concreta da história, adverte Santos (2002, p. 101), "não separa o natural e o artificial, o natural e o político, devemos propor outro modo de ver a realidade, oposto a esse trabalho secular de purificação, fundado em dois pólos distintos". Aliás, com relação à historicidade, cabe ainda salientar que a "natureza" em si é a-histórica - a história é memória, consciência temporal que os humanos possuem em relação aos fatos passados, que, aliados à capacidade de reflexão, possibilita relacioná-los com acontecimentos do presente, vislumbrando, por fim, o futuro. Como salienta Freire (2000a, p. 20), "a história que se processa no mundo é aquela feita pelos seres humanos".

\section{Paulo Freire e a visão crítica da Educação Ambiental}

Por toda a sua vasta obra, Freire sustenta a tese de que somos, concomitantemente, sujeitos e objetos do meio vital (geográfico). Logo, como agente determinante da própria transformação, cabe ao homem assumir a responsabilidade sobre seus atos. Nesse imperativo reside a "ética universal do ser humano", que, segundo Freire (1996):

Condena a exploração da força de trabalho do ser humano, que condena acusar por ouvir dizer, afirmar que alguém falou A sabendo que foi dito B, falsear a verdade, iludir o incauto, golpear o fraco e o indefeso, soterrar o sonho e a utopia, prometer sabendo que não cumprirá a promessa [...] é por esta ética inseparável da prática educativa, não importa se trabalhamos com crianças, jovens ou com adultos, que devemos lutar. (FREIRE, 1996, p. 17)

Essa ética, ao longo do processo de convivência social, pode tomar dois caminhos: um que a ratifica e outro que a nega. Consequentemente, é pela primeira possibilidade que a educação precisa se pautar, não apenas em 
sua vertente socioambiental, mas como um todo. Interdisciplinar por essência, a educação denominada socioambiental ${ }^{5}$, de inspiração freireana, implica construir coletivamente uma consciência crítica acerca do presente vivido que promova "a denúncia de como estamos vivendo e o anúncio de como poderíamos viver". Tanto o que "poderá vir se retificações forem feitas nas políticas denunciadas como o que pode ocorrer se, pelo contrário, tais políticas se mantiverem" (FREIRE, 2000b, p. 118-19). É interdisciplinar, uma vez que a sua efetivação inclui a compreensão da história, o esclarecimento dos "porquês" mais radicais do real percebido, abrigando, ainda, uma visão global da inter-relação das forças econômicas, sociais, espaciais e ideológicas, entre outras, que uma análise como essa requer. Afinal, como assevera Santos (2002, p. 20), "uma disciplina é uma parcela autônoma, mas não independente, do saber geral".

Acreditamos que à educação socioambiental cabe promover, entre outros aspectos, a conscientização do quanto é importante a participação política de cada membro da sociedade no que diz respeito tanto ao uso do espaço público quanto do privado, em se tratando das normas que o regulamentam. Pois o que se processa em um ambiente privado pode repercutir no público, bem como o inverso, constatação que salienta a necessária responsabilidade da ação humana sobre todo e qualquer espaço, juntamente com os objetos nele contidos (em especial os chamados "recursos naturais"). Esse engajamento pode auxiliar na ampliação necessária do debate em torno dos problemas ambientais e sociais, evitando concentrá-los apenas na esfera governamental e nas ONGs, instituições que vêm se multiplicando nos últimos tempos.

A ação dos homens, mais precisamente da sociedade, em seu modo de produção e consumo sobre o meio geográfico, para Freire, é característica da sua própria natureza (o termo natureza usado no sentido de essência, definindo o humano como um ser de relação com os outros e com o mundo). Somos os únicos capazes de objetivar e agir sobre o nosso meio de forma intencional, transformadora. Entretanto, como vimos, a ação seguida de transformação em escala mais significativa está reservada a poucos indivíduos, enquanto a grande maioria resta imersa na ação ingênua, mecânica e controlada ideológica e politicamente pelos "opressores". Para haver uma ruptura com essa constatação, chamamos a atenção, a partir de Freire, para a Educação Problematizadora e sua possível ação conscientizadora. 
A concepção problematizadora da educação é aquela que respeita a natureza do homem, percebendo-o como o ser (unicamente) capaz de objetivar o espaço que o cerca através da práxis, união entre a teoria (pensar) e a prática (agir), construindo sua própria leitura acerca do real. A ação tem correspondência na encarnação do dever ser constitutivo do humano, concretude da existência. Compreender a vida como evento em curso acentua a ação histórica, definidora de verdades e constituidora de sujeitos, em que participar se traduz em transformar, concomitantemente, a mim mesmo e ao entorno, lembrando que "para viver, preciso ser inacabado" (BAKHTIN, 2003, p. 11). Por sua vez, essa compreensão da realidade em permanente processo constitui no homem a sua consciência, que pode ser tal qual a realidade lhe é apresentada. Diante disso, a conscientização representa um aprofundamento da tomada de consciência através de um novo processo de apreensão da realidade em sua relação com o estar sendo daquele que a observa - o sujeito. Isso implica transcender o mero espontaneísmo de espectador passivo diante dos fatos, uma vez que são muitos os meios dispostos a trazê-los até nós, através de uma ação mediadora.

Sendo um conhecimento interno, a conscientização ${ }^{6}$ possui dois focos de ação: um em relação a si próprio e outro em relação aos demais seres humanos, considerando todos em seu meio de vida (meio geográfico). A primeira dimensão compreende o sujeito histórico, o "eu no mundo", capaz de trazer a realidade percebida para dentro de si e refletila, agindo coerentemente com um "pensar certo". Por estar voltada para si, nessa dimensão a conscientização é autoconhecimento. Porém é forçoso que esse conhecimento também ocorra na esfera dos outros seres humanos, do "eu" em relação aos outros, entendendo-os como semelhantes em sentimentos, necessidades, direitos e deveres na sociedade: é o reconhecimento ao mesmo tempo de si e do outro. Finalmente, complementando o ato de conhecer-se e reconhecer-se, a conscientização como um processo histórico de busca e de libertação encontra seu ápice na ação transformadora da realidade. Fiori (2002, p. 10), no prefácio da Pedagogia do Oprimido, aponta que a "conscientização não é apenas conhecimento e reconhecimento, mas opção, decisão, compromisso". E a ação que os seres humanos efetuam sobre o meio geográfico constitui um processo dialético de constante transformação mútua entre consciência e mundo. Por sua vez, sendo a consciência uma capacidade unicamente 
humana que possibilita conhecer e reconhecer, agir e transformar, é igualmente possível inferir um sentido de responsabilidade que resulta dos seus atributos. Freire (2000a) destaca que o homem tem na responsabilidade uma exigência fundamental para o exercício da sua liberdade, pois condicionado, e não simplesmente determinado, pode ser visto como um ser de decisão e de ruptura, logo, de intervenção no mundo.

A responsabilidade a que Freire se refere faz parte de um conjunto de valores indispensáveis para que este mundo, resultado da intervenção humana, venha a ser constituído de acordo com o sonho utópico: mais justo, livre da miséria e da opressão. A favor da vida, "entendida na totalidade da extensão do conceito e não só vida humana" e contra toda e qualquer prática que a negue. Quer seja "poluidora do ar, das águas, dos campos, ou devastadora das matas" (FREIRE, 2000b, p. 132).

\section{Considerações finais}

Do conjunto de reflexões desenvolvidas e ainda inacabadas, restamos convictos de que a superação dos dualismos enraizados culturalmente, como é o caso da formulação natureza-ser humano, dependerá da transformação das consciências. E essa é uma tarefa que cabe ao processo educativo, seja escolar, familiar, formal ou não-formal. Vimos que, através da Educação "Problematizadora", Freire estabelece princípios com o fito de romper com as injustiças sociais, historicamente construídas concomitantemente à evolução tecnológica e forçosamente apartadas de seu vínculo com as questões ambientais. Essa perspectiva educacional estrutura e fomenta a capacidade de luta e de indignação do oprimido em qualquer contexto, metas audaciosas que sugerem questionar em que medida podem ser alcançadas. A educação possui uma dimensão política que pretende, ao prover o indivíduo de condições intelectuais autônomas, despertar a perspectiva de reconhecer-se como sujeito ativo do todo, que é a sociedade civil.

Salientamos a emergência de novos questionamentos, reveladores da complexa teia de elementos envolvidos na análise da qual nos ocupamos. Com relação ao vigor da ação conscientizadora, será que homens e mulheres, vivendo o rigor de uma realidade miserável, sem perspectivas de futuro, conseguirão se reconhecer como atores dentro da 
sociedade? Que tipo de reação provoca no indivíduo humilhado diariamente a reflexão sobre si mesmo, sobre sua situação? E ainda, quais as vinculações ideológicas possíveis de serem desenvolvidas entre as questões ambientais e o problema da injustiça social? Afinal, homens e mulheres não dependem mais somente das possibilidades naturais para sobreviver. Vivem em função de condições artificiais, criadas pelos humanos, provocadoras de novas necessidades e dependências, não pouco geradoras de submissão e exploração mútuas.

Para além das muitas indagações suscitadas, constata-se que, para Rousseau, Santos e Freire, evolutivamente, homens e mulheres continuaram sendo oprimidos e explorados frente às relações entre suas necessidades (básicas e supérfluas) e as diferentes capacidades para satisfazê-las. Estruturou-se uma organização social que se sustenta exatamente nesta contradição: a coexistência da diferença (desigualdade) social, oprimidos e opressores, como aponta Freire. Fomentando a acumulação para poucos perante a miséria de muitos, continua repartindo desigualmente as riquezas socialmente produzidas, escamoteando o fato de que "as mesmas forças produtivas que produziram, na forma do sistema de mercado, a crise ecológica e a crise das relações entre os sexos são responsáveis por um desemprego em massa, crescente e global” (KURZ, 1997, p. 51). Toda essa dinâmica contraditória, embora hegemônica, provoca o desejo contínuo pela igualdade de condições de consumo. E essa igualdade não é, certamente, aquela de que falam tanto Rousseau quanto Freire, pois, na atualidade, corresponde ao sujeito do consumo, celebrado pela parcela dominante das relações de produção.

A partir de Freire, destacamos que conhecimento e reconhecimento, imbricados no processo de conscientização, são imperativos paralelos na construção de uma práxis cada vez mais coletiva acerca dos problemas ambientais e sociais em conjunto, provocados e sentidos no meio, entendido como espaço de vida em comum. Ao harmonizar indivíduo, sociedade e meio geográfico, a Educação Problematizadora revela-se a corrente educacional capaz de proporcionar a educandos e educadores uma nova forma de pensar os problemas ambientais, considerados então como socioambientais. Salientando o caráter ideológico do conhecimento e a necessidade de problematizá-lo, o educador pernambucano ratifica o pensamento de Santos (2002, p. 238), para quem a "união entre técnica e ciência vai dar-se sob a égide do mercado". Entendem ambos que o 
poder do capital implica transformações espaciais a partir de intencionalidades unilaterais, dirigidas por uma ótica exploratória e sem limites.

Consequentemente, a educação socioambiental, amparada pela concepção problematizadora, transcende o ecologismo preservacionista em sua visão reducionista dos contextos vividos, visando à construção de um novo paradigma, através da ruptura com a racionalidade do mercado. Preocupa-se em reverter os quadros de resignação de grande parte da sociedade diante dos desequilíbrios por ela mesma provocados, em um momento de globalização e urbanização crescentes. Para além de um ambiente ecologicamente equilibrado, sadio, a educação socioambiental que propomos contempla (como autêntico dever-ser) uma qualidade de vida digna para todos, sustentada por uma sociedade radicalmente justa e democrática, coerente com a unidade entre homem e natureza, a ser recontextualizada nos diferentes tempos e espaços vividos.

\section{Referências}

BAKHTIN, Mikhail. Estética da criação verbal. 4 ed. Trad. Paulo Bezerra. São Paulo: Martins Fontes, 2003.

CASSETI, Valter. Ambiente e apropriação do relevo. São Paulo: Difel, 1985.

FIORI, Ernani Maria. Aprender a dizer a sua palavra. In: FREIRE, Paulo. Pedagogia do Oprimido (prefácio). São Paulo: Paz e Terra, 2002.

FREIRE, Paulo. Pedagogia da autonomia. São Paulo: Paz e Terra, 1996.

FREIRE, Paulo. À sombra desta mangueira. São Paulo: Olho d'água, 2000a.

FREIRE, Paulo. Pedagogia da indignação. São Paulo: Unesp, 2000b.

GONÇALVES, Walter P. Os (des)caminhos do meio ambiente. São Paulo: Contexto, 1996.

KURZ, Robert. Os últimos combates. Petrópolis, RJ: Vozes, 1997.

MENDONÇA, Francisco de Assis. Geografia e meio ambiente. São Paulo: Contexto, 1994.

MORAES, Antonio C. R. Meio ambiente e ciências humanas. São Paulo: Hucitec, 1994.

MORIN, Edgar. Educação e complexidade: os sete saberes e outros ensaios. São Paulo: Cortez, 2002.

ROUSSEAU, Jean-Jacques. Os devaneios do caminhante solitário. Trad. Fúlvia Maria Moretto. Brasília: Editora Universidade de Brasília, 1995.

ROUSSEAU, Jean-Jacques. Discurso sobre a origem e os fundamentos da desigualdade entre os homens. São Paulo: Martins Fontes, 1999a.

ROUSSEAU, Jean-Jacques. Emílio, ou, Da educação. São Paulo: Martins Fontes, 1999b. SANTOS, Milton. A natureza do espaço. São Paulo: Edusp, 2002. 


\section{Notas}

${ }^{1}$ A Geografia é, por origem, uma ciência "de caráter eminentemente ambientalista", a única que, desde a sua sistematização, "se propôs o estudo da relação entre os homens e o meio natural do planeta" (MENDONÇA, 1994, p. 22).

${ }^{2}$ A analogia com o meio natural proposta por Milton Santos é viável, embora com ressalvas. O destaque pré-social da noção rousseauniana rechaça qualquer indício de vinculo coletivo, exceto entre mães e filhos durante o tempo de dependência biológica, o que não é previsto no período de vigência do meio natural. Consideramos que reside apenas na insignificância do poder transformador que o homem exerce no espaço imediato o fator comum entre ambas as noções.

${ }^{3}$ Tratado sobre educação que corresponde a uma das principais obras de Rousseau, escrito em 1757 e publicado no ano seguinte.

${ }^{4}$ O pensamento de Rousseau é repleto de noções consideradas embrionárias de ideias atuais, em áreas como Política, Educação, Filosofia, Antropologia, entre outras. A maneira como enfoca a totalidade existencial remete ao "pensamento complexo" proposto por Edgar Morin (2002, p. 19), que almeja "a relação de inseparabilidade e as interretroações entre qualquer fenômeno e seu contexto, e deste com o contexto planetário".

${ }^{5} \mathrm{O}$ uso do termo socioambiental se justifica na busca por afirmar a relação indissociável entre as questões sociais e ambientais, destacadas constantemente ao longo do texto. Vale lembrar que o ambiente existe como ambiente humano, apropriado socialmente.

${ }^{6}$ Freire entende a consciência como um atributo humano que permite a cada pessoa ter noção da sua própria existência em relação à realidade que a cerca, fruto de um processo dialético e construtivo em curso permanente, que tem no inacabamento a característica principal. Nesse processo, a tensão entre objetividade e subjetividade revela a existência humana em seus limites e possibilidades: nem totalmente livre nem totalmente determinado pelas circunstâncias, sujeito e objeto, como destacamos anteriormente.

Recebido: $23 / 03 / 08$

Aprovado: 21/09/09

Contato:

Universidade Federal de Pelotas Instituto de Ciências Humanas Laboratório de Cartografia e Estudos Ambientais Rua Alberto Rosa, 154 - sala 14

Porto

Pelotas - RS

CEP 96015-710 